\title{
A Dual-Permeability Approach to Study Anomalous Moisture Transport Properties of Cement-Based Materials
}

\author{
${\text { Zhidong } \text { Zhang }^{1} \text { (D) } \cdot \text { Ueli Angst }}^{1}$
}

Received: 14 June 2019 / Accepted: 23 August 2020 / Published online: 4 September 2020

(c) The Author(s) 2020

\begin{abstract}
Anomalous moisture transport in cement-based materials is often reported in the literature, but the conventional single-porosity moisture transport models generally fail to provide accurate simulation results. Previous studies suggested that the anomalous moisture transport could be caused by different moisture transport velocity in large and small pores. Based on this concept, the present study proposes a continuous dual-permeability model for cement-based material. The proposed model includes the transport contribution of both liquid water and water vapor, which are governed by liquid advection and vapor diffusion, respectively. We explicitly consider that moisture transport in the large pore region is faster than the small pore region. The volumetric fraction of each region is determined when fitting the measured sorption isotherms by using a bimodal equation. The validation with experimental data shows that the dual-permeability model can well simulate both the "normal" and the anomalous moisture transport. The applicability of the proposed model implies that the "dual-porosity property" could be one of reasons that cause anomalous moisture transport in cementitious materials. In addition, results show that vapor diffusion can be neglected for moisture transport in both porosities at high relative humidity (RH), while at low RH, vapor diffusion must be considered.
\end{abstract}

Keywords Water vapor sorption isotherm · Permeability · Van Genuchten-Mualem model $\cdot$ Moisture transfer factor $\cdot$ Volumetric fraction

Electronic supplementary material The online version of this article (https://doi.org/10.1007/s1124 2-020-01469-y) contains supplementary material, which is available to authorized users.

Zhidong Zhang

zhangzhi@ethz.ch

Ueli Angst

ueli.angst@ifb.baug.ethz.ch

1 Institute for Building Materials (IfB), ETH Zurich, 8093 Zurich, Switzerland 


\section{Introduction}

The moisture state in cement-based materials is related to their durability (Baroghel-Bouny et al. 2017). Aggressive agents (e.g., chloride) can penetrate into concrete with liquid water (e.g., Nilsson 1985; Liu et al. 2018; Baroghel-Bouny et al. 2012; Mao et al. 2019). When concrete is unsaturated, carbon dioxide $\left(\mathrm{CO}_{2}\right)$ can rapidly diffuse into the pores that are not filled with liquid water. These processes are able to cause corrosion of the reinforced steel (rebar) and deterioration of concrete structures (Angst 2018). Therefore, appropriate moisture transport models are essential for the predication of structures durability. Conventionally, a moisture transport model based on the Darcy's or Fick's law is used to predict the moisture state in cement-based materials (e.g., Bazant and Najjar 1972; Coussy 1995; Mainguy et al. 2001). However, concerning anomalous moisture transport reported in the literature (e.g., Wadsö 1992; Hall et al. 1995; Taylor et al. 1999; Saeidpour and Wadsö 2015a), the conventional models fail to predict the mass change of a specimen.

Anomalous moisture transport is found in both water uptake (liquid absorption) and drying of the cement-based materials. Hall and his colleagues considered an anomalous process as that the measured curve of mass change $(\Delta m)$ versus square root of time $\left(t^{1 / 2}\right)$ does not obey the linear relation (Hall et al. 1995; Taylor et al. 1999). Recent studies showed that this square root mass change curve has two linear stages (Ren et al. 2019). The first linear stage follows the results of conventional single-porosity model, while the second linear stage deviates from the first linear stage, which is why such a mass change curve is called anomaly. Some other studies reported the anomalous mass change curves which follow the fourth root functions (e.g., Alderete et al. 2020), which is certainly different from the most data reported in the literature (Hall et al. 1995; Zhou et al. 2017; Zhang and Scherer 2018).

When the moisture transport occurs in the hygroscopic range, the case that the measured mass change (loss or increase) curves do not follow the curves calculated by Fick's law has been termed as anomalous moisture transport ( Wadsö 1992). Saeidpour and Wadsö (2015a) reported anomalous mass change curves when cement paste samples were subject to drying/wetting in a dynamic vapor sorption (DVS) analyzer.

In the literature, various reasons have been proposed to explain the anomalous moisture transport. These reasons can be categorized into two main groups: the microstructural change and the complex pore structure.

1. Microstructural change. The macroscopically observed drying shrinkage is induced by the microscopic damages of pores due to the relatively large capillary force established during water evaporation (Scherer 2015). The microstructural rearrangement during drying was observed by ${ }^{1} \mathrm{H}$ nuclear magnetic resonance relaxometry (Maruyama et al. 2019). During water uptake, the swelling of hydration products (mainly calcium-silicate-hydrate, $\mathrm{C}-\mathrm{S}-\mathrm{H}$ ) was observed by either the environmental scanning electron microscope (ESEM) (Hall et al. 1995) or nuclear magnetic resonance (NMR) (Zhou et al. 2017). This microstructural change is generally considered to be caused by chemical interactions of water with C-S-H. Hall et al. (1995) argued that the anomalous water absorption in cement-based materials is caused by re-hydration of unreacted cement and dehydrated components of hardened cement pastes. Zeng and Xu (2017) also assumed reaction kinetics occurring along with moisture transport in cement pastes. The effect of microstructural alterations on moisture transport is rarely considered by the moisture transport models in the literature. Hall (2019) proposed to use a time-dependent perme- 
ability to simulate the sorptivity during water absorption. Our recent study reported that by considering the effect of microstructural change (via the time-dependent permeability and the water content-dependent permeability), the simulation accuracy of mass loss during drying cement pastes is largely improved (Zhang and Angst 2020).

2. Complex pore structure. Cement-based materials have a broad pore size distribution, ranging from micropores ( $\mathrm{nm}$ size) to macropores ( $\mu \mathrm{m}$ and $\mathrm{mm}$ size), which are classified as large and small capillary pores, gel pores, and interlayer pores (Mindess and Young 1981). Nevertheless, most of the moisture transport models are developed on the basis of the single-porosity concept, meaning that transport properties in different sizes of pores are not distinguished. The concept of dual-porosity to explain anomalous moisture transport in cementitious materials was introduced in Zhang et al. (2018b) and the shapes of various anomalous mass loss curves can be well fitted by the empirical dual-porosity equation. Hamilton and Hall (2018) considered that the second linear stage of a water absorption curve is caused by the slow gas dissipation into pore solution in the long-term water absorption, while the other studies believe that the second stage can be ascribed to the slow water transport in small pores (Zhang et al. 2018b; Alderete et al. 2020).

The present study aims at evaluating whether the complex pore structure could be one of reasons for anomalous moisture transport. The complex pore structures are represented by the dual-porosity concept and moisture transport in different porosities is considered by introducing a dual-permeability model.

\section{The Dual-Porosity/Dual-Permeability Concept}

The dual-porosity/dual-permeability concept is widely used in geoscience for simulating mass transport in soils and fractured media (e.g., Barenblatt et al. 1960; Warren and Root 1963; Zimmerman et al. 1993; Chen 1989). It was also adapted to other porous materials, such as food (Wallach et al. 2011) and coal (Nikoosokhan et al. 2012). The concept of dual-porosity/dual-permeability model was originated from the study of Barenblatt et al. (1960) on saturated water flow in fissured rocks. In that work, the natural fracture network and the intact rock matrix were simulated as two overlapping porous media with their own porosity, permeability, and fluid pressure fields. The water flow was fulfilled by Darcy's law with the transfer of liquid between the fissures and the pores. Most of the subsequent dual-permeability models followed the same concept as Barenblatt et al. (1960). These models contain three permeabilities: one for the fracture, one for the matrix and one for the fracture-matrix interface. The last one describes the exchange of flows at the interface of the two porous regions. In the simplified dual-porosity model (no flow in the matrix) proposed by Warren and Root (1963) for naturally fractured media, the flux at the interface was considered to be proportional to the pressure difference in these two regions. Gerke and van Genuchten (1993a, 1993b) calculated the interface permeability as the mean of permeabilities of matrix and fracture. In this model, Richards' equation was used to govern water flow in both regions. Two water retention curves, one for the matrix and one for the fracture, were formulated by van Genuchten (VG) equation (van Genuchten 1980) and the relative permeabilities were calculated by the van-Genuchten-Mualem (VGM) equation (van Genuchten 1980; Mualem 1976). Since then, this set of equations was commonly 
found in the literature for modeling unsaturated moisture transport in porous media (Köhne et al. 2002, 2006; Ma and Shao 2008; Smyl et al. 2017).

The application of dual-porosity/dual-permeability concept to cement-based materials is only found in a few studies. Carlier and Burlion (2011) and Zhang et al. (2014) borrowed the dual-porosity concept and used the bimodal equation proposed by Durner (1994) to fit the measured sorption isotherms. They found that the use of the bimodal equation could show much better agreements between experimental data and theoretical curves, especially for extremely high and low degrees of saturation. Nevertheless, the uncertainty of fitting is higher because of more undetermined parameters in the bimodal equation. Recently, Smyl et al. (2017) used a dual-permeability modeling approach to simulate water flow in fractured cement-based materials with micro-cracks. A new equation for the water transport coefficient across matrix-fracture interface was proposed to take into account permeabilities of both regions. Their simulation results showed that the classical model failed to adequately describe the long-term water ingress in fractured materials, whereas the dualpermeability model well simulated moisture transport in late stages of water ingress.

When adapting the dual-permeability model from geoscience to cement-based materials, we must know that (1) the moisture transport mechanisms in materials with fine pores such as cement-based materials are different from soils (granular materials) or rocks (fractured media), and (2) the volumetric fraction of each region is not directly measurable for the undamaged cement-based materials. Concretes in the natural condition are often unsaturated; thus, a moisture transport model should consider two phases at least, liquid and vapor (Mainguy et al. 2001). For soils or fractured media, the volumetric fraction of each region can be estimated from the aggregate-macropores ratio (Gerke and van Genuchten 1993b; Köhne et al. 2002, 2006) or the measured volume of the fracture system (Berkowitz et al. 1988). The volumetric fraction of fracture in damaged concrete was experimentally determined with a microscope (Smyl et al. 2017). However, it is very often found that the boundary between two porosity regions is arbitrarily chosen in the literature with vague criteria (Kodikara et al. 1999). For these cases, the volumetric fraction was set as a free parameter (e.g., Ma and Shao 2008) and determined by fitting the experimental data. In regard to undamaged cement-based materials, it is not easy to determine the volume for each porosity region since there is no a clear boundary between two regions.

To tackle these issues for cement-based materials, the present study proposes a twophase moisture transport model (e.g., Mainguy et al. 2001; Zhang et al. 2015) for the dualpermeability modeling and the volumetric fraction is determined when fitting the measured sorption isotherms by using a bimodal equation (Durner 1994). Experimental data for anomalous moisture transport, measured by a DVS instrument (Saeidpour and Wadsö 2015a), are used to validate the proposed modeling approach.

\section{Applying the Dual-Permeability Concept to Cement Paste}

\subsection{Structure of Cementitious Materials}

When cement is mixed with water, hydration products immediately grow from the surfaces of the cement particles. Initially, the flake-like structure appears and eventually becomes the needle-like structure (Zhang et al. 2018a). The impingement of hydration products from the adjacent cement grains creates a pore network composing of various sizes of pores. If simply separating these pores into two groups with large and small 
pores, the hydrated cement paste can be viewed as a dual-porosity material with two regions, large pore region and small pore region. We assume that pores in each region are well connected, meaning that fluids can move in each region, as well as communicate between two regions. This indicates that definitions of large and small pores in this study are based on the moisture transport properties in pores. For this case, two regions cannot be separated by a single value of pore size because this boundary between two regions varies with the moisture transport properties. This is why in this study terms like "large" and "small" pores are used, other than "macropore" and "micropore" or "capillary" and "gel" pores because there terms always imply that pores in two regions are in a fixed pore size range.

The porosity and degree of saturation of each region can thus be determined based on the dual-porosity concept. Volumes occupied by different phases for a material with two porosity regions are illustrated in Fig. 1. Let us define the total porosity $\phi$ of a cement paste as the total pore volume $V_{p}$ per unit volume of the material $V_{t}$; that gives $\phi=V_{p} / V_{t}$. Similarly, porosities of the large and small pore regions are defined as $\phi_{l}=V_{p, l} / V_{t}$ and $\phi_{s}=V_{p, s} / V_{t}$ (see illustrations in Fig. 1). Then, we have $\phi=\phi_{l}+\phi_{s}$.

The degree of saturation $S$ in each region is calculated according to Fig. 1, written as $S_{l}=V_{w, l} / V_{p, l}$ and $S_{s}=V_{w, s} / V_{p, s}$, respectively. The total degree of saturation is

$$
S=\frac{V_{w, l}}{V_{p, l}+V_{p, s}}+\frac{V_{w, s}}{V_{p, l}+V_{p, s}}
$$

If defining the volumetric fraction of large pore region as $w_{f}=V_{p, l} /\left(V_{p, l}+V_{p, s}\right)$, the total degree of saturation is rewritten as

$$
S=w_{f} S_{l}+\left(1-w_{f}\right) S_{s}
$$

Thus, porosities of the large and small pores regions are calculated by

$$
\phi_{l}=w_{f} \phi ; \quad \phi_{s}=\left(1-w_{f}\right) \phi
$$

Note that the definition of $w_{f}$ is different from that in Gerke and van Genuchten (1993a) which included the volume of non-porous solid phase. Assuming no solid in the large pore region $\left(V_{l}=V_{p, l}\right), w_{f}$ should be multiplied by the total porosity $\phi$ to give the same value as that in Gerke and van Genuchten (1993a).

Fig. 1 Definition of porosity in a material with two porosities. Abbreviations are: $s=$ small pores, $l=$ large pores, $w=$ water occupied volume, and $p=$ pores volume

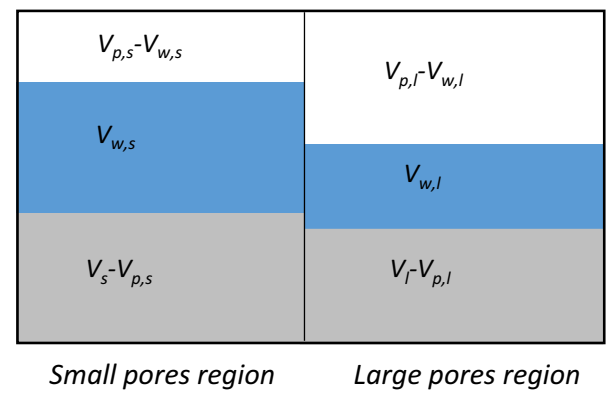




\subsection{Mass Exchange Between Two Porosity Regions}

As mentioned above, both linear and nonlinear mass transfers between the large pores and small pores were studied in the literature for the fractured media. It has been shown that the linear mass exchange was able to accurately represent the mass exchange between two porosity regions (Gerke and van Genuchten 1993b), which is written as:

$$
\Gamma_{w}=\beta_{w}\left(\mathrm{RH}_{s}-\mathrm{RH}_{l}\right)
$$

where $\beta_{w}\left(\mathrm{~kg} / \mathrm{s} / \mathrm{m}^{3}\right)$ is the first-order rate coefficient, which is generally assumed to be dependent on the geometry of the small pore region, the length scale of the large pores region and permeability at the interface of two regions (Gerke and van Genuchten 1993b, a). For concrete, Smyl et al. (2017) let $\beta_{w}$ be a function of the liquid conductivity in two porosity regions. In this study, we simplify the relation as the following expression.

$$
\beta_{w}=\xi k_{r, l} k_{r, s}
$$

where $\xi\left(\mathrm{kg} / \mathrm{s} / \mathrm{m}^{3}\right)$ is the moisture transfer factor and $k_{r, i}$ is the relative liquid permeability $(i=l$ or $s)$.

Concerning the case of cement paste, the moisture transfer factor $\xi$ is not directly measurable. In this study, we firstly let $\xi$ be a free parameter that will be determined by fitting the mass change curve measured during drying/wetting tests and then find a value that works for the studied cementitious materials.

\subsection{Determination of $w_{f}$ Based on Measured Sorption Isotherm}

For the single-porosity moisture transport model, a unimodal equation is able to describe the sorption isotherm. The most widely used one is the VG equation (van Genuchten 1980).

$$
S=\left[1+\left(\frac{P_{\mathrm{c}}}{\alpha}\right)^{\frac{1}{1-m}}\right]^{-m}
$$

where $\alpha(\mathrm{Pa})$ and $m(-)$ are parameters determined by fitting the measured sorption isotherm and $P_{\mathrm{c}}(\mathrm{Pa})$ is capillary pressure.

A bimodal equation that is used for the dual-porosity model is obtained by applying the VG equation for each porosity region; therefore, Eq. (2) becomes

$$
S=w_{f}\left[1+\left(\frac{P_{\mathrm{c}}}{\alpha_{l}}\right)^{\frac{1}{1-m_{l}}}\right]^{-m_{l}}+\left(1-w_{f}\right)\left[1+\left(\frac{P_{\mathrm{c}}}{\alpha_{s}}\right)^{\frac{1}{1-m_{s}}}\right]^{-m_{s}}
$$

Although the bimodal equation is able to provide a high fitting accuracy, the fitted parameters are subject to a relatively large uncertainty because of more parameters in the bimodal equation than the unimodal equation (Carlier and Burlion 2011; Zhang et al. 2014). To decrease the uncertainty, one way is to reduce the number of parameters. In VG equation, the air-entry pressure related parameter $\alpha_{i}$ should be different for the large and small pores (Ippisch et al. 2006), but the shape parameter $m$ was found in a very narrow range $(0.4-0.5)$ for OPC pastes with water-to-cement ratios from 0.35 to 0.6 (Zhang et al. 2014). The previous study suggested a constant value $(0.45)$ for the studied OPC pastes (Zhang 
et al. 2014). Therefore, only three parameters in Eq. (7) need to be determined by fitting the measured sorption isotherm, namely, $w_{f}, \alpha_{l}$, and $\alpha_{s}$.

\subsection{Transport Model in Unsaturated Porous Materials}

Moisture transport in unsaturated porous media can be simulated by either multi-, two- or single-phase models (Coussy 1995; Zhang et al. 2015). For the general purpose of focusing on the mass change, a two-phase model is sufficient, including the liquid transport under the gradient of liquid pressure and vapor diffusion under the gradient of vapor density. The governing equations for the mass balance in 1D are written for the large and small pores as (Baroghel-Bouny 2007b; Zhang et al. 2015)

$$
\begin{gathered}
\rho_{w} \frac{\partial S_{l}}{\partial t}=\frac{1}{\phi_{l}} \frac{\partial}{\partial x}\left(-\rho_{w} \frac{K_{w, l} k_{r, l}}{\eta} \nabla P_{w, l}-D_{v 0} f_{l} \nabla \rho_{v, l}\right)+\frac{\Gamma_{w}}{\phi w_{f}} \\
\rho_{w} \frac{\partial S_{s}}{\partial t}=\frac{1}{\phi_{s}} \frac{\partial}{\partial x}\left(-\rho_{w} \frac{K_{w, s} k_{r, s}}{\eta} \nabla P_{w, s}-D_{v 0} f_{s} \nabla \rho_{v, s}\right)-\frac{\Gamma_{w}}{\phi\left(1-w_{f}\right)}
\end{gathered}
$$

where $\rho_{w}$ and $\rho_{v, i}\left(\mathrm{~kg} / \mathrm{m}^{3}\right)$ are the densities of liquid water and vapor, respectively; $P_{w, i}$ $(\mathrm{Pa})$ is the liquid pressure, $\eta(\mathrm{Pa} \cdot \mathrm{s})$ represents the dynamic viscosity of liquid water, $K_{w, i}$ $\left(\mathrm{m}^{2}\right)$ is the liquid intrinsic permeability, $D_{v 0}\left(\mathrm{~m}^{2} / \mathrm{s}\right)$ is the free vapor diffusion coefficient in the air, and $f_{i}$ represents the resistance factor for vapor diffusion and includes the reduction of accessibility for water vapor diffusion due to the presence of the solid and liquid phases, the tortuous path for diffusion, the different connectivities in the pore network, etc. Because of limited experimental results, the expression of $f_{i}=f_{i}\left(S_{i}, \phi_{i}\right)$ is generally derived from theoretical concepts. One equation that has been used for cement-based materials is given as Coussy (1995)

$$
f_{i}\left(S_{i}, \phi_{i}\right)=\phi_{i}\left(1-S_{i}\right) \alpha(S) \tau_{i}
$$

where $\phi_{i}\left(1-S_{i}\right)$ is the space available for vapor diffusion and $\alpha(S) \tau_{i}$ represents the tortuosity of the sole gaseous phase in the porous material and is written as Millington and Quirk (1961)

$$
\alpha(S) \tau_{i}=\phi_{i}^{x_{D}-1}\left(1-S_{i}\right)^{x_{D}+1}
$$

where parameter $x_{D}=2.74$ as suggested by Thiéry et al. (2008) for cement-based materials.

The relative permeability $k_{r, i}$ is a unique function of $S_{i}$ and calculated by the well-known VGM equation (van Genuchten 1980; Mualem 1976).

$$
k_{r, i}\left(S_{i}\right)=S_{i}^{0.5}\left[1-\left(1-S_{i}^{1 / m}\right)^{m_{i}}\right]^{2}
$$

This moisture transport model assumes the quasi-equilibrium between liquid and vapor within each porosity region. At the equilibrium state, the relation between capillary pressure $P_{\mathrm{c}}$ and relative humidity RH is governed by Kelvin's law. Note that the equilibrium assumption is not valid between two porosity regions since mass exchange is always occurring if the pressure/RH difference exits, unless, when a drying or wetting process reaches 
the mass equilibrium state and therefore $\mathrm{RH}$ in the small pores becomes the same as that in the large pores and no mass exchange exits any more. Furthermore, the imposed (Dirichlet) boundary condition is used for all simulations to simply the model.

Overall, two intrinsic permeabilities $\left(K_{w, l}\right.$ and $\left.K_{w, s}\right)$ and the moisture transfer factor $(\xi)$ need to be calibrated by experimental data, such as the measured mass change curves and moisture content profiles. The first two are the moisture transport properties that control the "inner" moisture transport. The latter is used for the moisture exchange between two porosity regions, and it can be viewed as a constant as will be shown in this paper. Thus, $K_{w, l}$ and $K_{w, s}$ are two undetermined parameters in proposed dual-permeability model.

\section{Experimental Validation}

To validate the proposed model for the undamaged cement paste, experimental data are collected from the literature. The experimental validation starts from the measured "normal" moisture transport that can be well simulated by a single-porosity model, and then moves to anomalous moisture transport that cannot be calculated by the single-porosity model. This way is able to check the applicability of the dual-permeability model to the anomalous moisture transport.

\section{1 “Normal” Moisture Transport}

Experimental data for the "normal" moisture transport were reported in Baroghel-Bouny (2007a), Nguyen (2009) and Zhang et al. (2015). Two cement pastes with water-to-cement (w/c) ratios 0.45 and 0.6 (denoted by $P 1$ and $P 2$ ) were made from the same OPC cement (CEM I 52.5, according to EN 197-1 European standard) and sealed in cylindrical plastic bottles for two years. Experimental data include sorption isotherms, drying mass loss curves and saturation profiles at the end of drying. Baroghel-Bouny measured the water vapor sorption isotherms by using the saturated salt solution method on small crushed samples (Baroghel-Bouny 2007a). Nguyen performed the drying tests by putting the cylindrical specimens (10 cm long and $7 \mathrm{~cm}$ in diameter) in a desiccator with constant $\mathrm{RH}$ at $53.5 \%$. The specimens were sealed by self-adhesive aluminum foil sheets, and only one side was open for moisture exchanges with the ambient environment. Saturation profiles were measured by the gamma-ray attenuation method at the end of drying tests (Nguyen 2009). Zhang et al. (2015) showed that measured mass loss curves and saturated profiles of these two cement pastes can be well simulated by a single-porosity model with $K_{w}$ as the only fitting parameter. In this section, the dual-permeability method is used for these two pastes as well to see if the proposed model is able to yield better results.

Results in Fig. 2 show that the fitted sorption isotherms for $P 1$ by the uni- and bimodal equations (Eqs. 6, 7) are almost identical. For $P 2$ paste, the bimodal equation shows slightly better fitting than the unimodal equation which misses the curve shape at high RH, such as RH $=97 \%$. The fitted $w_{f}$ for $P 1$ paste in Table 1 is greater than that for $P 2$ paste. This is reasonable because the low w/c paste is supposed to have a lower volumetric fraction of large pores than the paste with high w/c.

Unlike the conventional models that only employed the measured mass change curves to calibrate parameters, the present study needs to get good results for both measured mass loss curves and saturation profiles. For instance, the sorption isotherms of large and small pores for $P 1$ paste are identical, so to have good fitting of the measured mass loss curve, 


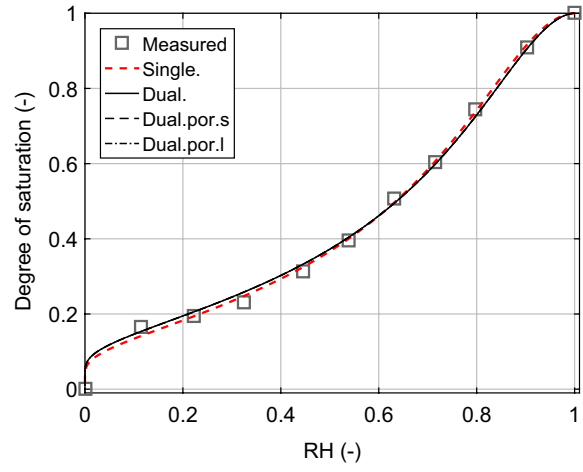

(a) P1 paste $(\mathrm{w} / \mathrm{c}=0.45)$.

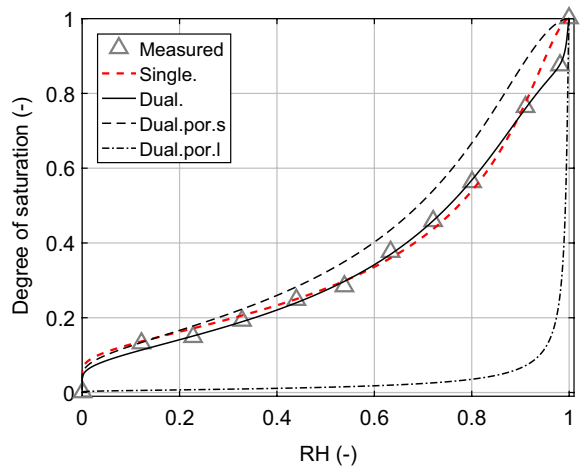

(b) P2 paste $(\mathrm{w} / \mathrm{c}=0.6)$.

Fig. 2 Water vapor desorption isotherms for the studied cement pastes. The fitted curves of $P 1$ paste for large and small pores are identical, so they are hidden

Table 1 Parameters used in simulations for two pastes

\begin{tabular}{llllll}
\hline Paste & Model & $\begin{array}{l}K_{w, s} \\
\left(\mathrm{~m}^{2}\right)\end{array}$ & $K_{w, l}\left(\mathrm{~m}^{2}\right)$ & $\xi$ & $w_{f}$ \\
\hline$P 1$ & Single & $1.75 \mathrm{E}-21$ & & - & - \\
& Dual & $9.71 \mathrm{E}-22$ & $2.47 \mathrm{E}-21$ & $1 \mathrm{E}-3$ & 0.10 \\
$P 2$ & Single & $2.6 \mathrm{E}-20$ & & - & - \\
& Dual & $8.16 \mathrm{E}-21$ & $1.08 \mathrm{E}-20$ & $1 \mathrm{E}-3$ & 0.16 \\
\hline
\end{tabular}

one could simply use the same value of $K_{w, l}$ as $K_{w, s}$. However, this would lead to a low fitting accuracy for the measured saturation profile because liquid permeabilities $\left(K_{w, i} k_{l, i}\right)$ and vapor diffusion coefficients $\left(D_{v, 0} f_{i}\right)$ are highly nonlinear. Therefore, the calibration by two different sets of experimental data can provide more stable and robust results.

In addition, we found that when $\xi$ is smaller than a certain value (1E-3 for $P 1$ and 1 for $P 2$ ), adjusting $\xi$ does not improve fitting accuracy (see discussion in Sect. 5.1). Thus, $\xi$ was assigned a value of $1 \mathrm{E}-3 \mathrm{~kg} / \mathrm{s} / \mathrm{m}^{3}$ for all simulations. As the result, only two parameters $\left(K_{w, l}\right.$ and $\left.K_{w, s}\right)$ are adjustable for simulations of the drying moisture transport in these two pastes.

Simulation results for two cement pastes clearly show that both modeling methods, single-porosity and dual-permeability, provide very similar results for measured mass loss curves and saturation profiles (see Fig. 3 for $P 1$ and figures in the Supplementary Materials for $P 2$ ). For $P 1$ paste, the mass loss from the small pores is higher than that from the large pores, which results from the high volumetric fraction of small pores. Regarding $P 2$ paste, because of the sharp drop of sorption isotherm at high RHs for the large pores, the mass loss contribution of large pores is very low compared to the small pores.

\subsection{Anomalous Moisture Transport}

Saeidpour and Wadsö (2015a) reported data for the anomalous moisture transport, in which Type I OPC, supplied by HeidelbergCement ${ }^{\circledR}$ (different source from measurements in the previous subsection), with $w / c=0.5$, was used. The cylindrical specimens were cast 


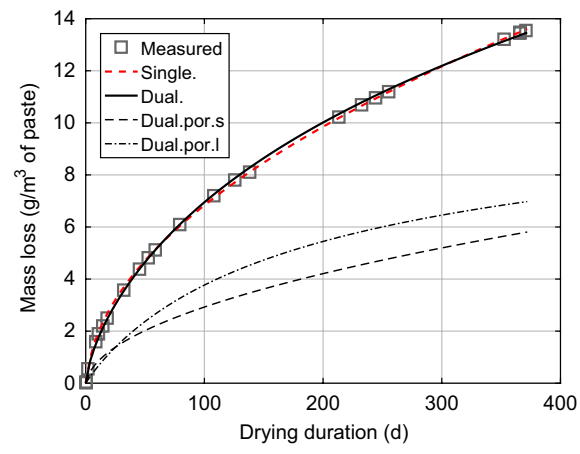

(a) Mass loss curves.

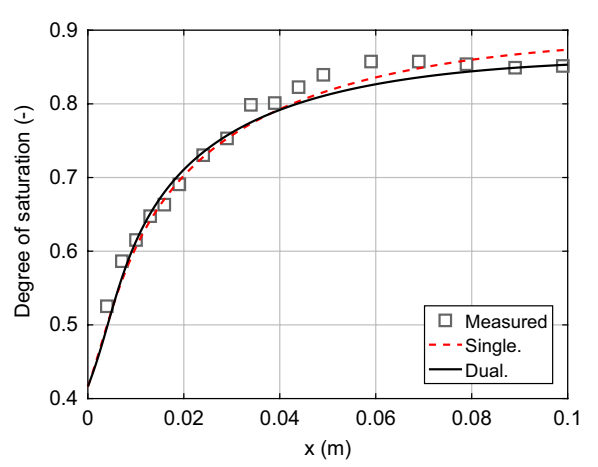

(b) Saturation profiles at the end of drying.

Fig. 3 Measured and simulated mass loss curves and saturation profiles for $P 1$ paste dried at $\mathrm{RH}=53 \%$

in small stainless steel tubes (inner diameter $5.5 \mathrm{~mm}$ and sample length $2.0 \mathrm{~mm}$ ) (Saeidpour and Wadsö 2015a) and then were sealed for about 3 months. Drying and wetting tests were carried out on different specimens in a DVS 1000 (Surface Measurement System Ltd., UK). The sorption isotherms, including desorption and adsorption, were measured on crushed samples in the same DVS (Saeidpour and Wadsö 2015b). The previous study has reported the measured isotherms and data processing (Zhang et al. 2018b).

Since moisture distribution in the specimens during drying/wetting was not measured, parameters were only adjusted to fit the measured mass change curves. This can certainly induce uncertainties; thus, to reduce the number of parameters and to have more consistent results, $\xi$ is kept at $1 \mathrm{E}-3 \mathrm{~kg} / \mathrm{s} / \mathrm{m}^{3}$ for all simulations. Similar to the previous section, two parameters $K_{w, l}$ and $K_{w, s}$ are used to fit experimental data.

Table 2 shows that the fitted $w_{f}$ for the desorption is lower than the adsorption. This can be explained by the fact that during drying some large pores inside the material are blocked by the small pores due to the "ink-bottle" effect; therefore, moisture transport in these large pores behaves more like moisture transport in the small pores and does not contribute to moisture transport in the large pores.

Fitted sorption isotherms in Fig. 4 clearly show that the unimodal equation cannot provide accurate results for both desorption and adsorption isotherms because most of the measured points are not close to the calculated curves. The advantage of using the bimodal equation is that it largely increases fitting accuracy compared with the unimodal equation. Similar to the desorption curve for $P 2$ paste, the sorption isotherms fitted by the bimodal equation for the large pores in Fig. 4 decrease sharply at the high RHs. This is expected due to the fact that liquid water in the large pores is removed quickly when the saturated sample is exposed to the unsaturated environment.

As the consequence of the less good fitting of the sorption isotherms, the simulated mass change curves by the single-porosity model do not match the measured ones (see the red dashed curves in Figs. 5 and 6 and more figures in the Supplementary Materials). Figure 4 shows that the slope of the fitted desorption curve by the unimodal equation in the range of $70-90 \% \mathrm{RH}$ is greater than that of the measured curve. As we know, the slope of a sorption isotherm is associated with the material's moisture capacity, which in principle represents the amount of moisture that can be removed by drying. The greater slope means that more moisture, which is apparently much more than the measured mass loss, 


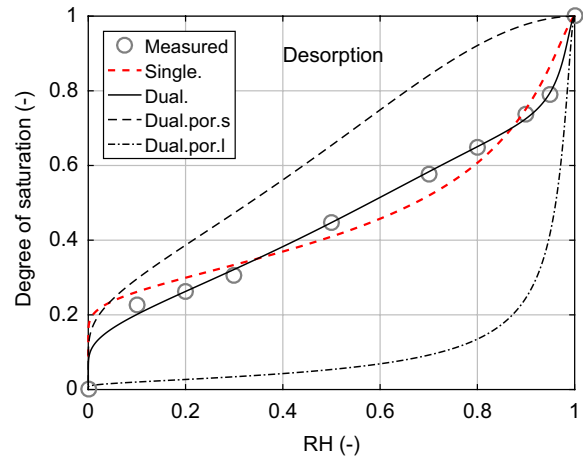

(a) Desorption isotherms.

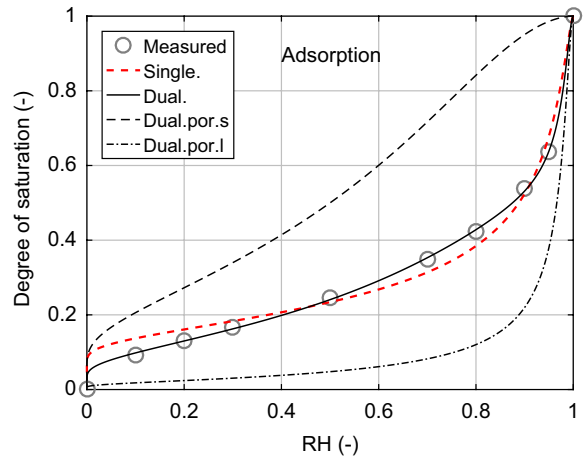

(b) Adsorption isotherms.

Fig. 4 Measured and fitted water vapor adsorption isotherms for the paste with anomalous moisture transport

Fig. 5 Mass loss curves for OPC paste dried at $\mathrm{RH}=80 \%$ from initially $90 \%$

Fig. 6 Mass increase curves for OPC paste wetted at $\mathrm{RH}=60 \%$ from initially $50 \%$
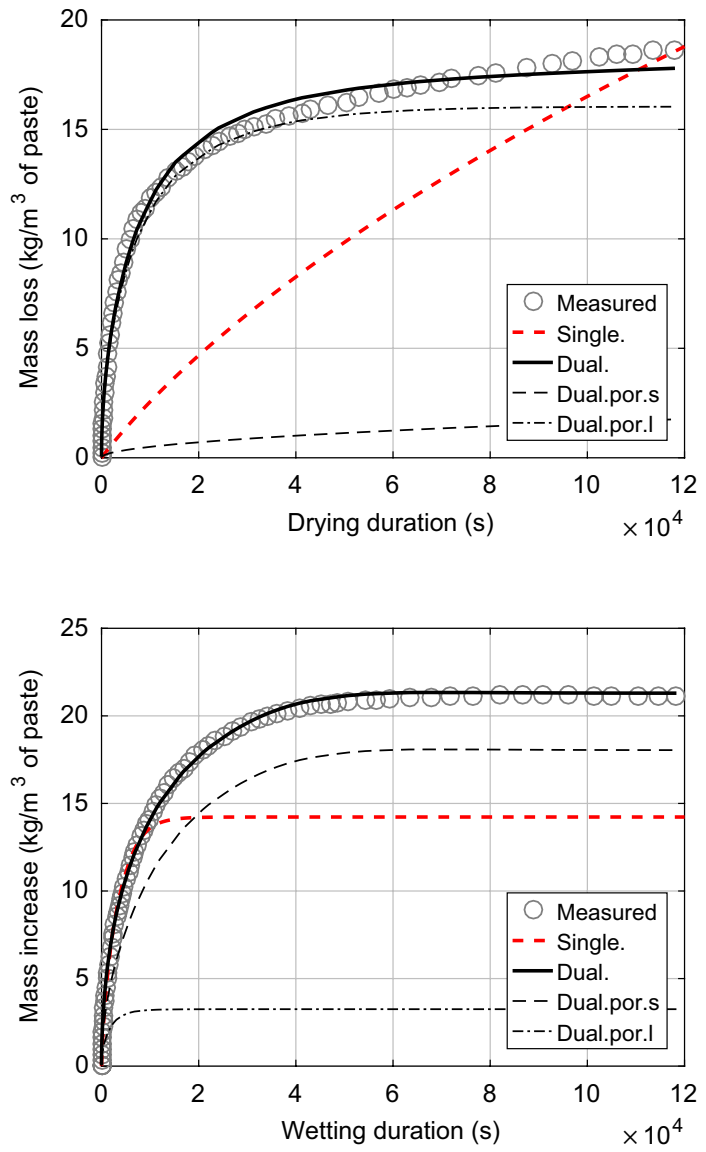
Table 2 Parameters obtained from fitting for anomalous moisture transport

\begin{tabular}{lllll}
\hline Cases & Model & $K_{w, s}\left(\mathrm{~m}^{2}\right)$ & $K_{w, l}\left(\mathrm{~m}^{2}\right)$ & $w_{f}$ \\
\hline Drying, RH $80 \% \rightarrow 70 \%$ & Single & $1 \mathrm{E}-21$ & & - \\
& Dual & $5.35 \mathrm{E}-24$ & $9.19 \mathrm{E}-19$ & 0.345 \\
Drying, RH 90\% $\rightarrow$ 80\% & Single & $1 \mathrm{E}-21$ & & - \\
& Dual & $2.44 \mathrm{E}-25$ & $9.77 \mathrm{E}-19$ & 0.345 \\
Wetting, RH 50\% $\rightarrow 60 \%$ & Single & $1 \mathrm{E}-18$ & & - \\
& Dual & $1.60 \mathrm{E}-21$ & $4.31 \mathrm{E}-17$ & 0.573 \\
Wetting, RH 60\% $\rightarrow 70 \%$ & Single & $1.2 \mathrm{E}-18$ & & - \\
& Dual & $6.43 \mathrm{E}-23$ & $1.04 \mathrm{E}-17$ & 0.573 \\
\hline
\end{tabular}

is expected to be removed from the specimen when it reaches the mass equilibrium. Contrarily, the fitted adsorption curve by the unimodal equation in the range of 50-60\% RH is gentler than the measured curve. As a result in Fig. 6, no matter how to adjust $K_{w}$, we could not make the calculated final mass by the single-porosity model increase close to the measured one. Because the calculated mass loss is much different from the measured one, the simulated curves become less sensitive to $K_{w}$.

For simulations with the dual-permeability model, we have very good results which closely match measured curves. If comparing results in this study with the fitted curves in Zhang et al. (2018b), it is clear that the analytical equation (dual-Weibull distribution function) used in Zhang et al. (2018b) provides even higher fitting accuracy than the proposed dual-permeability model, but parameters in the analytical equation are not associated with any physical meanings. However, if the objective is to extrapolate the final mass of the specimen in the measurement of sorption isotherms, the dual-Weibull distribution function may be adequate. In addition, the analytical equation can be used for the specimen with irregular geometry, which is very common in practice (e.g., sorption isotherm measurements in a dynamic vapor sorption analyzer).

The values of $K_{w, l}$ and $K_{w, s}$ in Table 2 show a scatter but if only comparing two drying (or wetting) cases, values of $K_{w, \Gamma}$ the main contributor to moisture transport-are very close. Of course, we could not find a set of $K_{w, l}$ and $K_{w, s}$ values that works well for both drying and wetting. This means that results from one drying/wetting condition may not be directly applicable to other conditions. Hence, the development of a universal dual-permeability model for all kinds of anomalous moisture transport need to consider more factors as stated in Introduction, such as chemical interactions of water with hydration products and the microstructural changes due to the change of moisture content.

When a single-porosity model is applicable, the dual-permeability model works as well, while the advantages of using a dual-permeability model are not significant. Therefore, we suggest that the dual-permeability model should be avoided for cases that a single-porosity model is applicable. In other words, the first step to perform the dual-permeability simulations is to ensure that the studied material has dual-porosity properties (more precisely, the large pore and the small pore regions as defined in Fig. 1). This can be done by checking if the measured sorption isotherm is well fitted with the unimodal equation. Otherwise, one can then try the dual-porosity/dual-permeability concept. 


\section{Discussion}

\subsection{Effects of Moisture Transfer Factor}

The moisture transfer factor $\xi$ controls the rate of moisture exchange between two regions. Examples in Fig. 7 show the effect of $\xi$ on the moisture transport in two porosities. It is clear that only when $\xi$ is larger than a certain value the effect on moisture transport can be seen in the mass change curves. This threshold value is case dependent as shown in Fig. 7 that $\xi \approx 50$ for drying and $\xi \approx 1 \mathrm{E} 4$ for wetting. These values are much greater than the one used for simulations $\left(1 \mathrm{E}-3 \mathrm{~kg} / \mathrm{s} / \mathrm{m}^{3}\right)$. If let $\xi$ be a free parameter for fitting, the value of $\xi$ was found very low (around $1 \mathrm{E}-9 \mathrm{~kg} / \mathrm{s} / \mathrm{m}^{3}$ ).

When cement-based materials are subjected to drying or wetting, $\mathrm{RH}$ in the large pores can reach the same level with the boundary RH faster than in the small pores because of the greater transport coefficients in the large pores. Therefore, during drying, a greater mass transfer factor results in faster moisture transfer from small pores to large pores. Meanwhile, moisture in the large and small pores evaporates, so moisture in the small pores become less with the increase in $\xi$ (see Fig. 7a). However, with more moisture accumulating in the large pores, it quickly evaporates to the environment because of the high transport coefficients of the large pores. This results in the stable moisture mass of the large pores but the higher total moisture loss from the specimen.

For wetting, a greater mass transfer factor can accelerate moisture condensation in the small pores from the large pores; this leads to more moisture increase in the small pore (see Fig. 7b). The high transport coefficients of the large pores ensure the stable moisture content in these pores. With the increase of moisture content in the small pores, the total mass of the specimen increases as well.

Fig. 7 indicates that if $\xi$ is further increased, moisture in small pores will be overdrawn for drying and overfilled for wetting. Therefore, large $\xi$ must be used with caution because it may cause unrealistic simulation results, unless, there is firm experimental evidence showing the great moisture transfer between the large and small pores. In this study, the low value of $\xi$ was found to best agree with the experimental data.

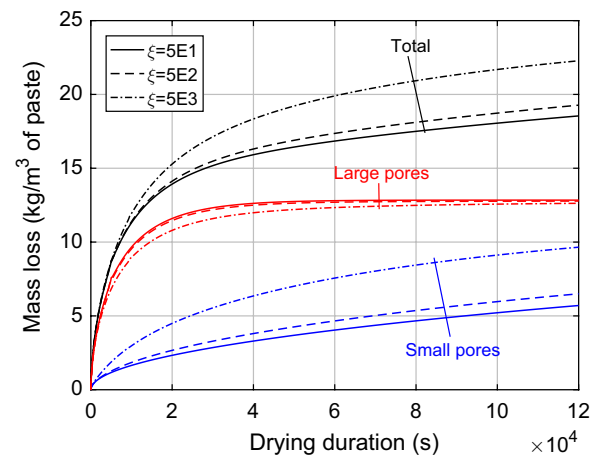

(a) Drying

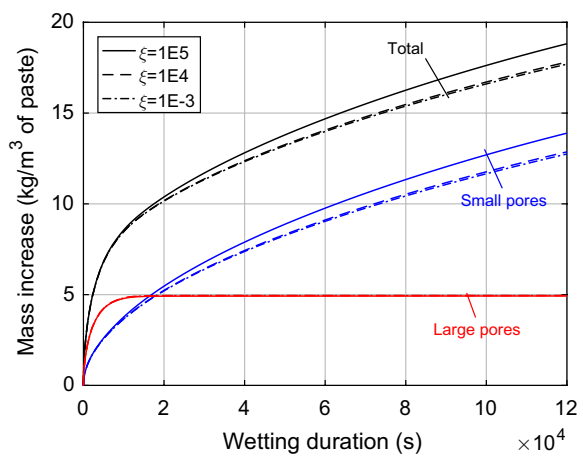

(b) Wetting

Fig. 7 Effect of mass transfer factor on moisture transport in the specimen and in small and large pores 


\subsection{Influence of Vapor Diffusion}

In most dual-permeability models, vapor diffusion is not considered (e.g., Barenblatt et al. 1960; Gerke and van Genuchten 1993a; Köhne et al. 2002, 2006; Ma and Shao 2008; Smyl et al. 2017). Here, we investigate if vapor diffusion is indeed negligible in the case of dualpermeability simulations. Two simulations without including the vapor diffusion term in Eqs.(8) and (9) were performed by taking two drying tests of anomalous moisture transport as examples. Results displayed in Fig. 8 show that the ignorance of vapor diffusion has a slight effect on drying at $\mathrm{RH}=80 \%$, whereas it greatly reduces the mass loss of drying at $\mathrm{RH}=70 \%$. This may imply that for drying at low RHs the contribution of vapor diffusion is not negligible.

The contribution of each phase (liquid or vapor) to the moisture transport can be assessed by calculating the apparent diffusivity $D_{a}$ considering the moisture transport as a pure diffusion-like process. Equations (8) and (9) thus are rewritten as

$$
\begin{gathered}
\frac{\partial S_{l}}{\partial t}=\frac{\partial}{\partial x}\left(D_{a, l} \frac{\partial S_{l}}{\partial x}\right)+\frac{\Gamma_{w}}{\rho_{w} \phi w_{f}} \\
\frac{\partial S_{s}}{\partial t}=\frac{\partial}{\partial x}\left(D_{a, s} \frac{\partial S_{s}}{\partial x}\right)-\frac{\Gamma_{w}}{\rho_{w} \phi\left(1-w_{f}\right)}
\end{gathered}
$$

where $D_{a, i}$ for each porosity system is expressed as

$$
D_{a, i}=-k_{r, i} \frac{K_{w, i}}{\phi_{i} \eta} \frac{\mathrm{d} P_{c, i}}{\mathrm{~d} S_{i}}-\left(\frac{M_{v}}{\rho_{w} R T}\right)^{2} D_{v 0} f_{i} \frac{P_{v s} R H_{i}}{\phi_{i}} \frac{\mathrm{d} P_{c, i}}{\mathrm{~d} S_{i}}
$$

The total $D_{a}$ for a material with dual-porosity is estimated by a similar equation to the degree of saturation (Eq. 2).

$$
D_{a} \approx w_{f} D_{a, l}+\left(1-w_{f}\right) D_{a, s}
$$

By using the determined $K_{w, s}$ and $K_{w, l}$ from drying at $\mathrm{RH}=80 \%$ in Table 2 , the calculated $D_{a, s}(R H)$ and $D_{a, l}(R H)$ curves are shown in Fig. 9. The shapes of these curves have been confirmed by the experimental result in the previous studies (Baroghel-Bouny 2007b;

Fig. 8 Effect of vapor diffusion on total mass loss in the dualpermeability model

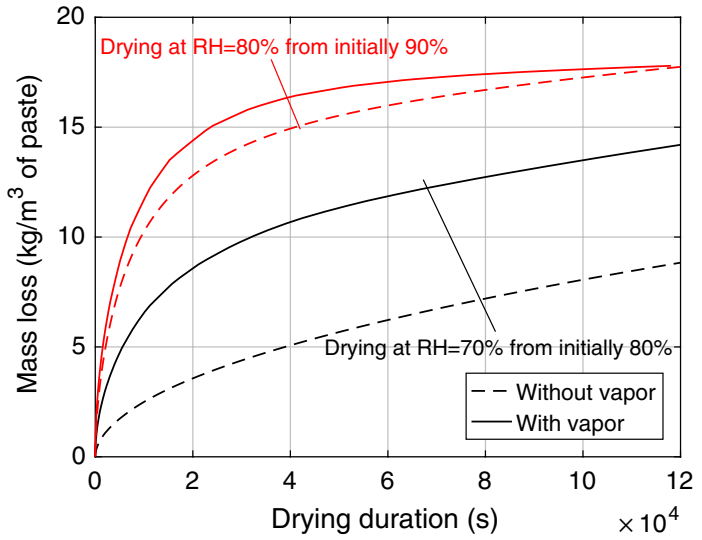


Fig. 9 Calculated apparent diffusivity $D_{a}$ (taking the case of drying at $\mathrm{RH}=80 \%$ as an example)

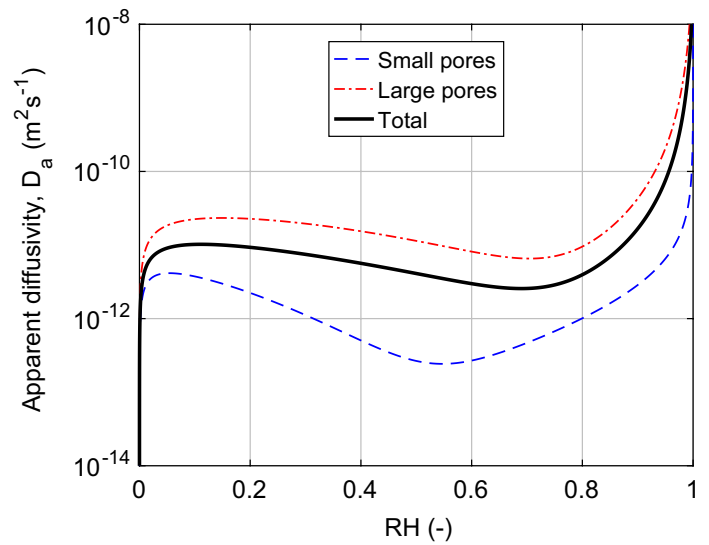

Zhang et al. 2016). The $D_{a, l}(R H)$ curve is always above the $D_{a, s}(R H)$ curve as permeability for large pores is much greater than that for the small pores. Figure 9 reveals that the moisture contribution of each phase varies with $\mathrm{RH}$, which shows that $D_{a}$ is high at low and high RHs [the trend was also observed in experimental data (Nilsson 1985; Ketelaars et al. 1995; Zhang et al. 2016)]. The lowest points of $D_{a, s}(R H)$ and $D_{a, l}(R H)$ curves, which is considered as the demarcation between the liquid and vapor transport dominant regions, are at $50 \%$ and $74 \%$, respectively. This agrees with the fact that liquid water in the small pores is less affected at high RH than that in the large pores. The comparison of mass loss for two drying cases in Sect. 4.2 shows that mass loss in the small pores for drying at $70 \% \mathrm{RH}$ becomes less than that for drying at $80 \% \mathrm{RH}$. It needs lower $\mathrm{RH}$ to remove or disconnect liquid water in the small pores. At the lowest point of the $D_{a}(R H)(\mathrm{RH}=70 \%$ in Fig. 9), the contribution for liquid water and vapor is comparable. This is the reason that Fig. 8 shows the non-negligible fraction of mass loss from vapor diffusion for drying at $70 \%$ RH.

\subsection{The Overall Permeability}

Based on the determined intrinsic permeabilities for two porosity regions, the overall intrinsic permeability of a cement paste $K_{w}$ is often calculated by the following equation in the literature (e.g., Gerke and van Genuchten 1993a; Smyl et al. 2017).

$$
K_{w}=\phi w_{f} K_{w, l}+\phi\left(1-w_{f}\right) K_{w, s}
$$

To verify this equation, $K_{w, l}$ and $K_{w, s}$ of $P 1$ and $P 2$ pastes are chosen to calculate $K_{w}$, because both single-porosity and dual-permeability models provide accurate fitting for these two pastes. The calculated $K_{w}$ are $4.6 \mathrm{E}-22$ and $4.2 \mathrm{E}-21 \mathrm{~m}^{2}$ for $P 1$ and $P 2$, respectively. Compared with the $K_{w}$ determined by the single-porosity model in Table 1 , the calculated ones are much lower.

The volumetric fraction factor $w_{f}$ represents the portion of the total pore volume occupied by large pores. It can be used to calculate the total water content or degree of saturation, but it is different from the transport contribution factor of each porosity region. According to the classical theories for permeability (Millington and Quirk 1961; Katz and Thompson 1987), permeability is not a linear function of the pore size, but a square function. This indicates that large pores have the higher permeability than the small pores even 
though they have the same volumetric fraction. This also indicates that the transport contribution factor of large pores should be much greater than $w_{f}$. Hence, in regard to calculating $K_{w}$, the use of $w_{f}$ as in Eq. (17) instead of the actual contribution to moisture transport can significantly underestimate the results.

\subsection{Microstructural Effect of Drying and Wetting}

In addition to the dual-porosity property, the microstructural changes during drying or wetting may lead to anomalous moisture transport, in particular when liquid transport happens in the small pores region whose structure is sensitive to water content. In an ESEM study, Fonseca and Jennings (2010) found that if a specimen is dried at a given RH (not directly to zero-RH) the morphology of hydration products at the microscopic scale is altered as a solid layer over $\mathrm{C}-\mathrm{S}-\mathrm{H}$ needles appears. After comparing different water removal methods, Zhang et al. (2018a) found that all drying methods can change the morphology of C-S-H to varying degrees. For instance, $\mathrm{C}-\mathrm{S}-\mathrm{H}$ fibers totally fall onto the cement grains for a harsh drying method (e.g., drying direct from water), while for a gentle drying approach (e.g., isopropanol replacement or supercritical drying), a thin film is created between two $\mathrm{C}-\mathrm{S}-\mathrm{H}$ fibers. By observing the in situ rehydration of the dried cement paste by an ESEM, Hall et al. (1995) found that the paste size was enlarged after it adsorbed water. The comparison of the pore size distributions measured by the mercury intrusion porosimetry for the dried sample and by NMR for the resaturated sample shows that PSD peaks for the resaturated sample shift to the finer pore range (Zhou et al. 2017), indicating that the resaturated sample was swelling. In summary, the morphological change of $\mathrm{C}-\mathrm{S}-\mathrm{H}$ during drying and wetting is illustrated by Fig. 10. After drying, the original needle-like structure partially collapses, which is recovered to a certain extent by rewetting, but cannot reach the same level as the original structure. Macroscopically, this is proved by the measured sorption isotherms (Wu et al. 2014) which show after the desorption-adsorption cycles that the total water content of the resaturated sample is lower than that of the saturated sample before measurement, indicating that the total porosity is smaller after the desorptionadsorption cycles.

All these morphological effects have a significant impact on the characteristics of micropores, such as pore structures, connectivity, etc. Consequently, the moisture transport properties are expected to be different from what we use in the proposed dual-permeability model. However, the microstructural alterations during drying or wetting are difficult to be quantified. To simplify the effect of the microstructural change on moisture transport, the time-dependent transport property is generally introduced (Hall 2019; Zhang and Angst 2020).

Fig. 10 Effects of drying and wetting on the morphology of hydration products. Drying results in the collapse of needlelike structures and only partial structures can be recovered after wetting

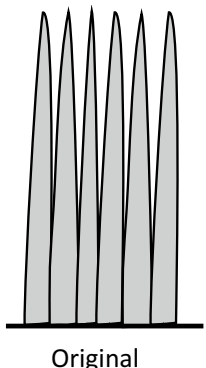

Original

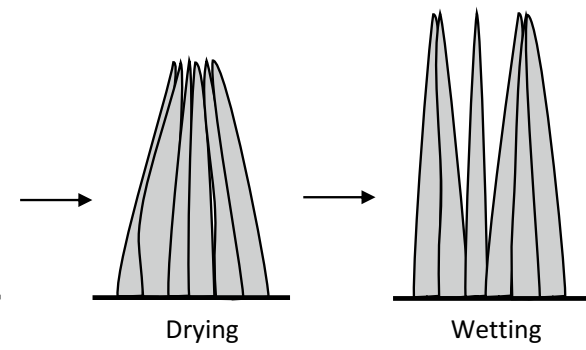




\subsection{Multi-porosity Concept}

While considering the concept of two-porosity still presents a simplification of the complex pore network, we find that this approach can significantly improve the prediction of moisture transport in cement pastes, in particular for the case so-called anomalous moisture transport. To further consider the complexity of the pore network, a multi-porosity model can be developed based on the concept of multi-porosity (Aifantis 1977). For cement pastes studied in this paper, the dual-porosity is sufficient enough to provide accurate fittings. But for uncracked concrete, the additional porosity may be added from the interfacial transition zone (ITZ) around aggregates because it is well known that the porosity of this zone is higher than the bulk concrete (Ollivier et al. 1995; Scrivener et al. 2004). The volumetric fraction of ITZ could be estimated based on the volume of aggregates and the assumed ITZ width (Garboczi and Bentz 1997). For cracked concrete, the cracks can be separated as a porosity region (Smyl et al. 2017). However, more porosity regions will lead to more parameters in the model to be fitted by experimental data. This will need much more experimental data which will largely decrease model's robustness.

\section{Conclusion}

Cement-based materials have a complex pore structure with pore sizes spanning from the nanometer to the millimeter range. Nevertheless, conventional approaches to model transport processes through the pore system are based on the single-porosity concept and fail to accurately describe experimental results of anomalous moisture transport. The present study proposes a dual-permeability model to better understand moisture transport in the complex pore system of cementitous materials. The pore system is divided into two regions, the large pores region and the small pores region. The model considers the contribution of both liquid water and water vapor to moisture transport. From the experimental validation, the following major conclusions can be drawn:

1. The dual-permeability model can well simulate the anomalous mass change curves for cement paste specimens dried/wetted at different RHs, while the single-porosity model finds poor agreement with the experimental data.

2. The applicability of the proposed dual-permeability model suggests that the "dualporosity property" could be one of the reasons that lead to anomalous moisture transport in cement pastes.

3. Vapor diffusion in either large or small pores is not negligible for moisture transport in the $\mathrm{RH}$ range below the demarcation point (the separation point between the liquid transport and vapor diffusion dominant regions) in the apparent diffusivity curve.

4. We found that only when the moisture transfer factor $\xi$ is larger than a certain value (depending on the material and drying or wetting condition) its effect on moisture transport can be seen in the mass change curves. The fitted value of $\xi$ in this study is very low, so we intentionally fixed $\xi=1 \mathrm{E}-3 \mathrm{~kg} / \mathrm{s} / \mathrm{m}^{3}$ for all materials.

5. This study proposes to determine the volumetric fraction of each porosity region by fitting the measured sorption isotherm with a bimodal equation. The proposed method works well for the studied materials. 
6. In the literature, it is generally found that the volumetric fraction is used to calculate the overall permeability. However, this study found that this method can largely underestimate the overall permeability. It suggests that the volumetric fraction is different from the transport contribution factor that should be used for the determination of the overall permeability.

7. When fitting the anomalous mass change curves, we could not find close values of permeability for different drying (or wetting) conditions. Therefore, the development of a universal dual-permeability model for anomalous moisture transport needs to consider more factors, such as chemical interactions of water with hydration products and the microstructural changes during drying/wetting.

Acknowledgment Open access funding provided by Swiss Federal Institute of Technology Zurich.

Funding The research was funded by the Swiss National Science Foundation (SNSF) through the ENDURE Project (Grant Number PP00P2-163675).

\section{Compliance with Ethical Standards}

Conflict of interest The authors declare that they have no conflict of interest.

Open Access This article is licensed under a Creative Commons Attribution 4.0 International License, which permits use, sharing, adaptation, distribution and reproduction in any medium or format, as long as you give appropriate credit to the original author(s) and the source, provide a link to the Creative Commons licence, and indicate if changes were made. The images or other third party material in this article are included in the article's Creative Commons licence, unless indicated otherwise in a credit line to the material. If material is not included in the article's Creative Commons licence and your intended use is not permitted by statutory regulation or exceeds the permitted use, you will need to obtain permission directly from the copyright holder. To view a copy of this licence, visit http://creativecommons.org/licenses/by/4.0/.

\section{References}

Aifantis, E.: Introducing a multi-porous medium. Dev. Mech. 8(37), 209-211 (1977)

Alderete, N.M., Zaccardi, Y.V., De Belie, N.: Mechanism of long-term capillary water uptake in cementitious materials. Cement Concr. Compos. 106, 103448 (2020)

Angst, U.M.: Challenges and opportunities in corrosion of steel in concrete. Mater. Struct. 51, 4 (2018)

Barenblatt, G., Zheltov, I.P., Kochina, I.: Basic concepts in the theory of seepage of homogeneous liquids in fissured rocks [strata]. J. Appl. Math. Mech. 24(5), 1286-1303 (1960)

Baroghel-Bouny, V.: Water vapour sorption experiments on hardened cementitious materials. Part I: Essential tool for analysis of hygral behaviour and its relation to pore structure. Cem. Concr. Res. 37(3), 414-437 (2007a)

Baroghel-Bouny, V.: Water vapour sorption experiments on hardened cementitious materials. Part II: Essential tool for assessment of transport properties and for durability prediction. Cem. Concr. Res. 37, 438454 (2007b)

Baroghel-Bouny, V., Wang, X., Thiéry, M., Saillio, M., Barberon, F.: Prediction of chloride binding isotherms of cementitious materials by analytical model or numerical inverse analysis. Cem. Concr. Res. 42, 1207-1224 (2012)

Baroghel-Bouny, V., Thiery, M., Dierkens, M., Wang, X.: Aging and durability of concrete in lab and in field conditions-pore structure and moisture content gradients between inner and surface zones in rc structural elements. Journal of Sustainable Cement-Based Materials 6(3), 149-194 (2017)

Bazant, Z.P., Najjar, L.J.: Nonlinear water diffusion in non-saturated concrete. Mater. Struct. 25, 3-20 (1972) 
Berkowitz, B., Bear, J., Braester, C.: Continuum models for contaminant transport in fractured porous formations. Water Resour. Res. 24(8), 1225-1236 (1988)

Carlier, J., Burlion, N.: Experimental and Numerical Assessment of the Hydrodynamical Properties of Cementitious Materials. Transp. Porous Media 86(1), 87-102 (2011)

Chen, Z.-X.: Transient flow of slightly compressible fluids through double-porosity, double-permeability systems-a state-of-the-art review. Transp. Porous Media 4(2), 147-184 (1989)

Coussy, O.: Mechanics of Porous Continua. Wiley, New York (1995)

Durner, W.: Hydraulic conductivity estimation for soils with heterogeneous pore structure. Water Resour. Res. 30, 211-233 (1994)

Fonseca, P., Jennings, H.: The effect of drying on early-age morphology of $\mathrm{C}-\mathrm{S}-\mathrm{H}$ as observed in environmental SEM. Cem. Concr. Res. 40, 1673-1680 (2010)

Garboczi, E.J., Bentz, D.P.: Analytical formulas for interfacial transition zone properties. Adv. Cem. Based Mater. 6(3-4), 99-108 (1997)

Gerke, H., van Genuchten, M.T.: A dual-porosity model for simulating the preferential movement of water and solutes in structured porous media. Water Resour. Res. 29, 305-319 (1993a)

Gerke, H., van Genuchten, M.T.: Evaluation of a first-order water transfer term for variably saturated dual-porosity flow models. Water Resour. Res. 29, 1225-1238 (1993b)

Hall, C.: Capillary imbibition in cement-based materials with time-dependent permeability. Cem. Concr. Res. 124, 105835 (2019)

Hall, C., Hoff, W., Taylor, S., Wilson, M., Yoon, B.-G., Reinhardt, H.-W., Sosoro, M., Meredith, P., Donald, A.: Water anomaly in capillary liquid absorption by cement-based materials. J. Mater. Sci. Lett. 14(17), 1178-1181 (1995)

Hamilton, A., Hall, C.: Beyond the sorptivity: definition, measurement and properties of the secondary sorptivity. ASCE J. Mater. Civ. Eng. 30(4), 04018049 (2018)

Ippisch, O., Vogel, H.-J., Bastian, P.: Validity limits for the van Genuchten-Mualem model and implications for parameter estimation and numerical simulation. Adv. Water Resour. 29, 1780-1789 (2006)

Katz, A., Thompson, A.: Prediction of rock electrical conductivity from mercury injection measurements. J. Geophys. Res.: Solid Earth 92(B1), 599-607 (1987)

Ketelaars, A., Pel, L., Coumans, W., Kerkhof, P.: Drying kinetics: a comparison of diffusion coefficients from moisture concentration profiles and drying curves. Chem. Eng. Sci. 50(7), 1187-1191 (1995)

Kodikara, J., Barbour, S., Fredlund, D., et al. Changes in clay structure and behaviour due to wetting and drying. In: Proceedings 8th Australia New Zealand Conference on Geomechanics: Consolidating Knowledge, p. 179. Australian Geomechanics Society (1999)

Köhne, J.M., Mohanty, B.P., Šimůnek, J., : Inverse dual-permeability modeling of preferential water flow in a soil column and implications for field-scale solute transport. Vadose Zone J. 5(1), 59 (2006)

Köhne, J.M., Köhne, S., Gerke, H.H.: Estimating the hydraulic functions of dual-permeability models from bulk soil data. Water Resour. Res. 38(7), 261-2611 (2002)

Liu, Q.-F., Feng, G.-L., Xia, J., Yang, J., Li, L.-Y.: Ionic transport features in concrete composites containing various shaped aggregates: a numerical study. Compos. Struct. 183, 371-380 (2018)

Ma, D., Shao, M.: Simulating infiltration into stony soils with a dual-porosity model. Eur. J. Soil Sci. 59(5), 950-959 (2008)

Mainguy, M., Coussy, O., Baroghel-Bouny, V.: Role of air pressure in drying of weakly permeable materials. J. Eng. Mech. 127, 582-592 (2001)

Mao, L.-X., Hu, Z., Xia, J., Feng, G.-L., Azim, I., Yang, J., Liu, Q.-F.: Multi-phase modelling of electrochemical rehabilitation for asr and chloride affected concrete composites. Compos. Struct. 207, 176-189 (2019)

Maruyama, I., Ohkubo, T., Haji, T., Kurihara, R.: Dynamic microstructural evolution of hardened cement paste during first drying monitored by $1 \mathrm{H}$ NMR relaxometry. Cem. Concr. Res. 122, 107117 (2019)

Millington, R., Quirk, J.: Permeability of porous solids. Trans. Faraday Soc. 57, 1200-1207 (1961)

Mindess, S., Young, J.: Concrete. Prentice Hall, Upper Saddle River (1981)

Mualem, Y.: A new model for predicting the hydraulic conductivity of unsaturated porous media. Water Resour. Res. 12, 513-522 (1976)

Nguyen, M.T.: Modélisation des couplages entre hydratation et dessiccation des matériaux cimentaires à l'issue du décoffrage. Ph.D. thesis, ENPC (2009)

Nikoosokhan, S., Vandamme, M., Dangla, P.: A poromechanical model for coal seams injected with carbon dioxide: from an isotherm of adsorption to a swelling of the reservoir. Oil Gas Sci. Technol. 67, 777-786 (2012)

Nilsson, L.-O.: Water and the hygro-thermal characteristics of hardened concrete. St-Remy-les-Chevreuse, France. FNB-Collège International des Sciences de la Construction, pp. 122-138 (1985) 
Ollivier, J., Maso, J., Bourdette, B.: Interfacial transition zone in concrete. Adv. Cem. Based Mater. 2(1), 30-38 (1995)

Ren, F., Zhou, C., Zeng, Q., Ding, Z., Xing, F., Wang, W.: The dependence of capillary sorptivity and gas permeability on initial water content for unsaturated cement mortars. Cement Concr. Compos. 104, 103356 (2019)

Saeidpour, M., Wadsö, L.: Evidence for anomalous water vapor sorption kinetics in cement based materials. Cem. Concr. Res. 70, 60-66 (2015a)

Saeidpour, M., Wadsö, L.: Moisture equilibrium of cement based materials containing slag or silica fume and exposed to repeated sorption cycles. Cem. Concr. Res. 69, 88095 (2015b)

Scherer, G.W.: Drying, shrinkage, and cracking of cementitious materials. Transp. Porous Media 110(2), 311-331 (2015)

Scrivener, K.L., Crumbie, A.K., Laugesen, P.: The interfacial transition zone (ITZ) between cement paste and aggregate in concrete. Interface Sci. 12(4), 411-421 (2004)

Smyl, D., Ghasemzadeh, F., Pour-Ghaz, M.: Can the dual-permeability model be used to simulate unsaturated moisture flow in damaged mortar and concrete? International Journal of Advances in Engineering Sciences and Applied Mathematics 9(2), 54-66 (2017)

Taylor, S., Hoff, W., Wilson, M., Green, K.: Anomalous water transport properties of portland and blended cement-based materials. J. Mater. Sci. Lett. 18(23), 1925-1927 (1999)

Thiéry, M., Belin, P., Baroghel-Bouny, V., and Nguyen, M.D.: Modelling of isothermal drying process in cementitious materials - analysis of the moisture transfer and proposal of simplified approaches. In: Proceedings of 3rd International Conference on Coupled T-H-M-C Processes in Geo-systems, pp. 571-581, Polytech Lille, France (2008)

van Genuchten, M.T.: A closed-form equation for predicting the hydraulic conductivity of unsaturated soils. Soil Sci. Soc. Am. J. 44, 892-898 (1980)

Wadsö, L.: A critical review on anomalous or non-fickian vapor sorption. Technical report, Rapport TVBM (Intern 7000-rapport); Vol. 7017. Division of Building Materials, LTH, Lund University, Sweden (1992)

Wallach, R., Troygot, O., Saguy, I.: Modeling rehydration of porous food materials: II. The dual porosity approach. J. Food Eng. 105, 416-421 (2011)

Warren, J., Root, P.J.: The behavior of naturally fractured reservoirs. SPE J. 3, 245-255 (1963)

Wu, M., Johannesson, B., Geiker, M.: A study of the water vapor sorption isotherms of hardened cement pastes: possible pore structure changes at low relative humidity and the impact of temperature on isotherms. Cem. Concr. Res. 56, 97-105 (2014)

Zeng, Q., Xu, S.: A two-parameter stretched exponential function for dynamic water vapor sorption of cement-based porous materials. Mater. Struct. 50, 128 (2017)

Zhang, Z., Angst, U.: Modeling anomalous moisture transport in cement-based materials with kinetic permeability. Int. J. Mol. Sci. 21(3), 837 (2020)

Zhang, Z., Scherer, G.: Determination of water permeability for a moisture transport model with minimized batch effect. Constr. Build. Mater. 191, 193-205 (2018)

Zhang, Z., Thiery, M., Baroghel-Bouny, V.: A review and statistical study of existing hysteresis models for cementitious materials. Cem. Concr. Res. 57, 44-60 (2014)

Zhang, Z., Thiery, M., Baroghel-Bouny, V.: Numerical modelling of moisture transfers with hysteresis within cementitious materials: verification and investigation of the effects of repeated wetting-drying boundary conditions. Cem. Concr. Res. 68, 10-23 (2015)

Zhang, Z., Thiery, M., Baroghel-Bouny, V.: Investigation of moisture transport properties of cementitious materials. Cem. Concr. Res. 89, 257-268 (2016)

Zhang, Z., Scherer, G.W., Bauer, A.: Morphology of cementitious material during early hydration. Cem. Concr. Res. 107, 85-100 (2018a)

Zhang, Z., Thiery, M., Baroghel-Bouny, V.: An equation for drying kinetics of cementitious materials. Dry. Technol. 36, 1446-1459 (2018b)

Zhou, C., Ren, F., Wang, Z., Chen, W., Wang, W.: Why permeability to water is anomalously lower than that to many other fluids for cement-based material? Cem. Concr. Res. 100, 373-384 (2017)

Zimmerman, R.W., Chen, G., Hadgu, T., Bodvarsson, G.S.: A numerical dual-porosity model with semianalytical treatment of fracture/matrix flow. Water Resour. Res. 29(7), 2127-2137 (1993)

Publisher's Note Springer Nature remains neutral with regard to jurisdictional claims in published maps and institutional affiliations. 